\title{
VERA-CS User Support Activities for PoR 14
}

Brendan Kochunas, University of Michigan $03 / 31 / 2017$

Approved for Public Release
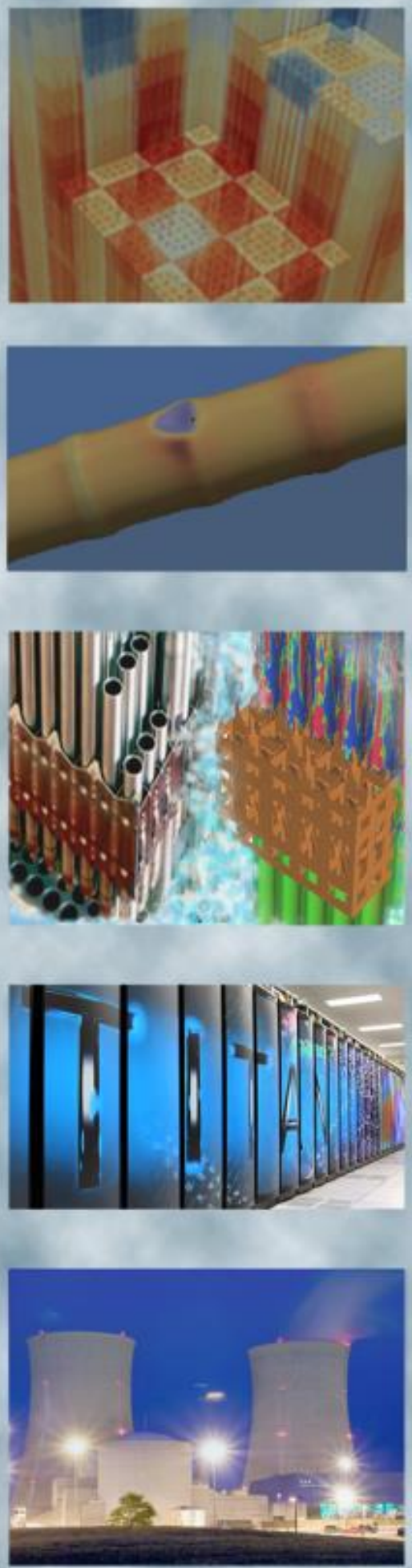


\section{REVISION LOG}

\begin{tabular}{|c|c|c|l|}
\hline Revision & Date & Affected Pages & \multicolumn{1}{c|}{ Revision Description } \\
\hline 0 & $03 / 31 / 2017$ & All & Initial Release \\
\hline & & & \\
\hline & & & \\
\hline & & & \\
\hline
\end{tabular}

\section{Document pages that are:}

Export Controlled No

IP/Proprietary/NDA Controlled No

Sensitive Controlled No

Unlimited All

This report was prepared as an account of work sponsored by an agency of the United States Government. Neither the United States Government nor any agency thereof, nor any of their employees, makes any warranty, express or implied, or assumes any legal liability or responsibility for the accuracy, completeness, or usefulness of any information, apparatus, product, or process disclosed, or represents that its use would not infringe privately owned rights. Reference herein to any specific commercial product, process, or service by trade name, trademark, manufacturer, or otherwise, does not necessarily constitute or imply its endorsement, recommendation, or favoring by the United States Government or any agency thereof. The views and opinions of authors expressed herein do not necessarily state or reflect those of the United States Government or any agency thereof.

\section{Requested Distribution:}

To:

Copy: 


\section{EXECUTIVE SUMMARY}

The purpose of this milestone is to document the user support activities that took place between 10/1/2016 and 3/31/2017 (PoR 14). In the normal PHI workflow, that also extends to several activities within RTM, a Kanban process is followed. This involves creating tickets for specific work items and track the progress to complete these specific work items.

The PHI Kanban is the primary source for the content of this report. The reader should note that there may be items missing from the report. Missing items would not be present for one of the following reasons:

1. The work was not documented using a Kanban ticket. Typically this applies to tasks that take less than an hour. Individually this may be a small item, but collectively over the PoR this may combine to non-trivial effort.

2. Information in the Kanban ticket was not properly entered. This happens more frequently than we think.

The scope of this report summarizes all activities related to VERA-CS user support activities; where those activities may be providing direct support or indirect support.

Discussion of work related to the following components such: BISON, MAMBA, Tiamat, Cicada, and Shift, and VERAView are not included.

User support activities related to providing installations or releases to users are not discussed in this report. There is a separate milestone (L3:PHI.INF.P14.04) and report documenting these activities over PoR 14.

During PoR 14 there were approximately 108 PHI Kanban tickets related to user support activities, either directly or indirectly. In total there were 108 tickets related to user support activities for VERA-CS. There were 56 new reported defects and 34 defects fixed in PoR 14. 44 tickets were related to miscellaneous user requests and did not directly support any milestones. Work was also performed for 30 tickets related to 7 milestones. A training was also given to WEC. 


\section{CONTENTS}

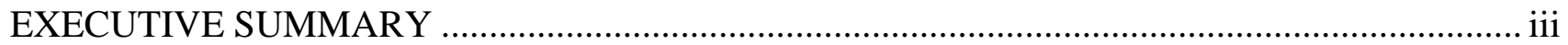

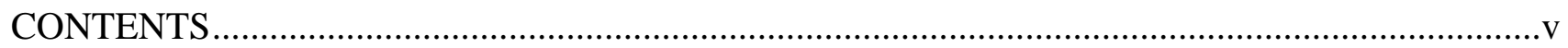

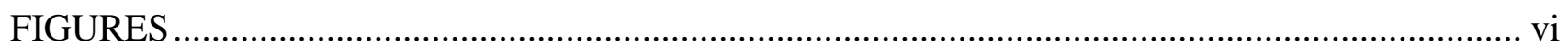

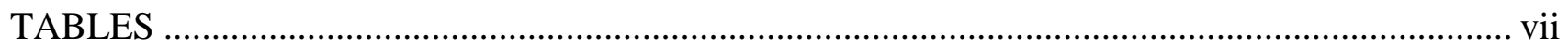

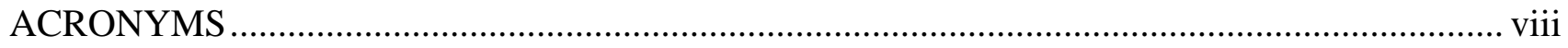

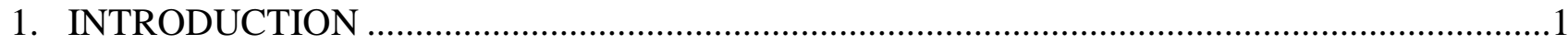

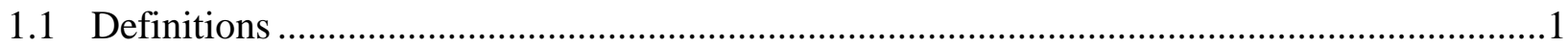

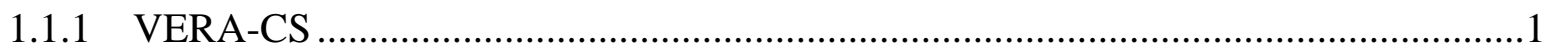

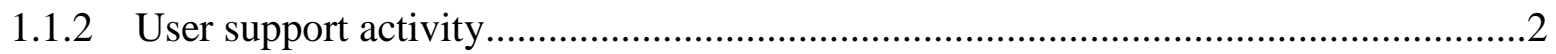

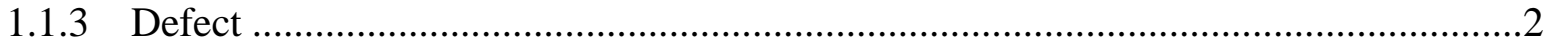

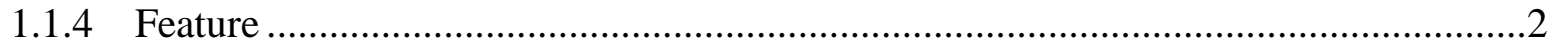

1.2 Categories of User Support Activities ........................................................................2

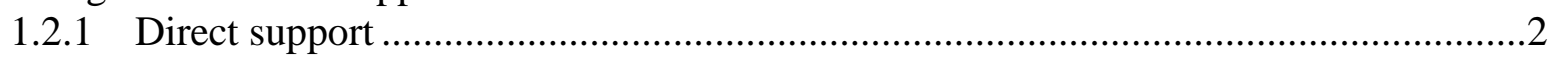

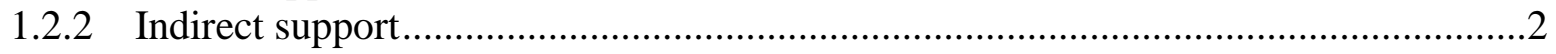

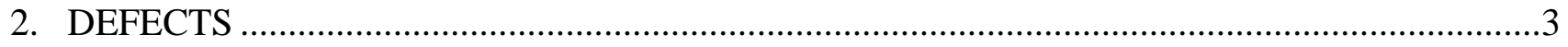

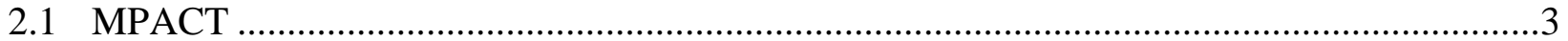

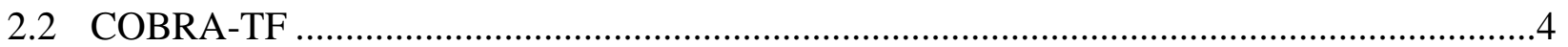

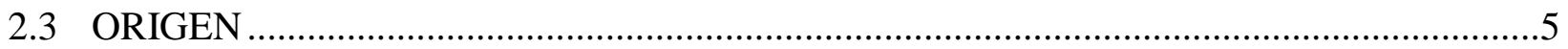

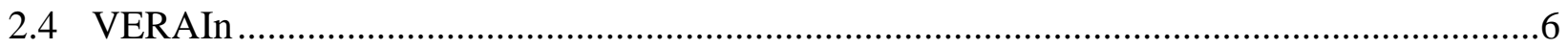

3. ACTIVITIES RELATED TO OTHER MILESTONES ...................................................

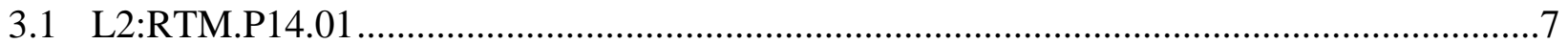

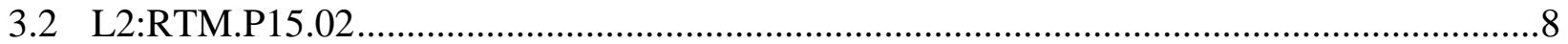

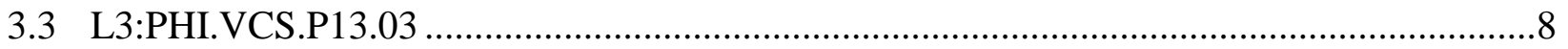

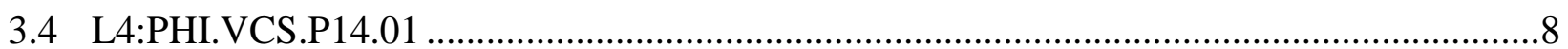

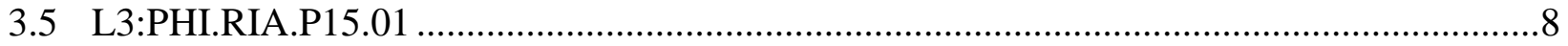

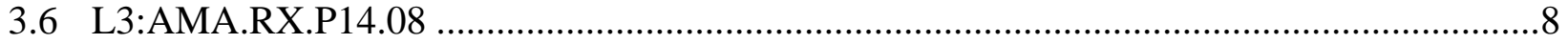

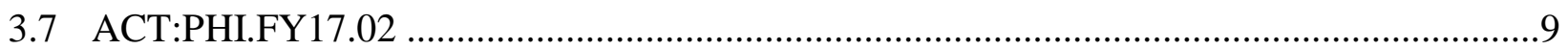

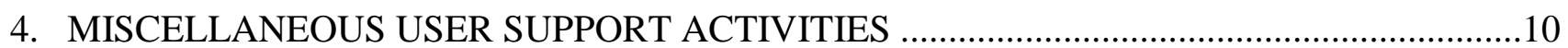

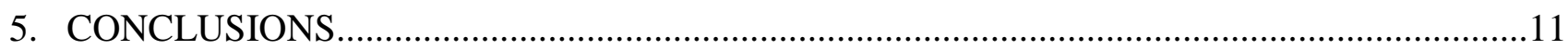

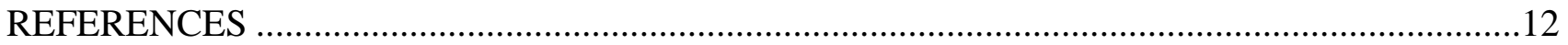


FIGURES 


\section{TABLES}

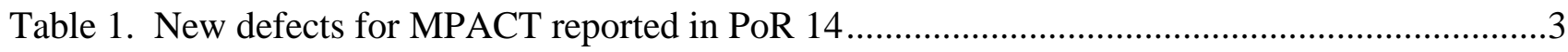

Table 2. Closed defects for MPACT reported in PoR 14 .....................................................4

Table 3. New defects for COBRA-TF reported in PoR 14 ....................................................4

Table 4. Closed defects for COBRA-TF reported in PoR 14 .....................................................5

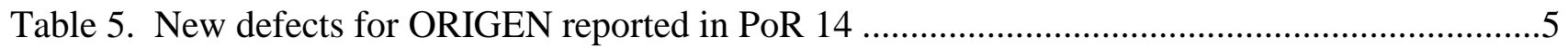

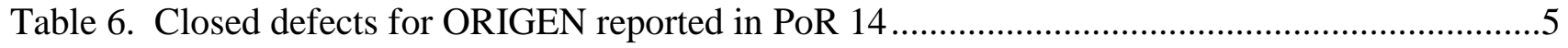

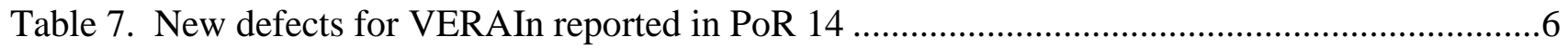

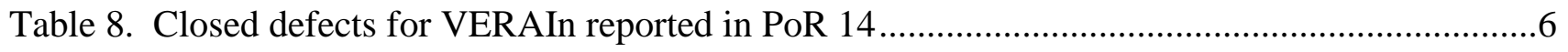

Table 9. Milestones supported during PoR 14 .................................................................

Table 10. Tickets supporting L2:RTM.P14.01 completed during PoR 14 ...................................7

Table 11. Tickets supporting L2:RTM.P15.02 completed during PoR 14 ...................................8

Table 12. Tickets supporting L3:PHI.VCS.P13.03 completed during PoR 14.............................8

Table 13. Tickets supporting L3:PHI.RIA.P15.01 completed during PoR 14 ..............................

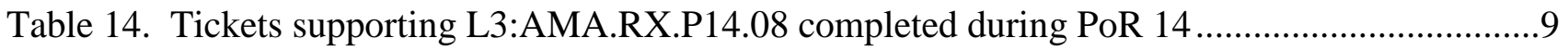

Table 15. Miscellaneous support activities completed during PoR 14 .......................................10 


\section{ACRONYMS}

BWR

CASL

CI

CE

CTF

DNB

IFBA

MAMBA

MPACT

MCNP

$\mathrm{NaN}$

PHI

PoR

PWR

RIA

RTM

UIUC

UM

VERA-CS

WEC boiling water reactor

Consortium for Advanced Simulation of Light Water Reactors

Continuous Integration

Combustion Engineering

COBRA-TF subchannel thermal-hydraulics code

departure from nucleate boiling

Integral Fuel Burnable Absorber

MPO advanced model for boron analysis

Michigan parallel characteristics transport code

Monte Carlo N-Particle

Not a Number

Physics Integration

plan of record

pressurized water reactor

reactivity insertion accident

Radiation Transport Methods

University of Illinois Urbana-Champaign

University of Michigan

Virtual Environment for Reactor Applications - Core Simulator

Westinghouse Electric Corporation 


\section{INTRODUCTION}

The purpose of this milestone is to document the user support activities that took place between 10/1/2016 and 3/31/2017 (PoR 14). In the normal PHI workflow, that also extends to several activities within RTM, a Kanban process is followed. This involves creating tickets for specific work items and track the progress to complete these specific work items. The format of this documentation is an HTML website that interfaces to an SQL database. This format is very useful for providing access, navigability, and record keeping. However, it is not particularly amenable to providing a coherent, complete, and distributable summary of activities.

CASL does the majority of its work scope definition and planning through milestones. However, there are regular tasks that arise that require individuals' efforts to address that were not necessarily contained within the scope of these milestones. From the software development side this can include fixing code defects, adding simple features to facilitate ease of use or analysis, adding major capabilities that enable new types of analyses, or research into potential methods to improve upon the existing methods. From an infrastructure point of view some of these activities can include deploying installations for individual users on target platforms, updating documentation or preparing a release, or providing user training or answering user questions via email. There is also analysis support to evaluate the accuracy of existing models or data and potentially improving upon these. Collectively, these activities may be thought of as user support activities.

The PHI Kanban is the primary source for the content of this report. The reader should note that there may be items missing from the report. Missing items would not be present for one of the following reasons:

1. The work was not documented using a Kanban ticket. Typically this applies to tasks that take less than an hour. Individually this may be a small item, but collectively over the PoR this may combine to non-trivial effort.

2. Information in the Kanban ticket was not properly entered. This happens more frequently than we think.

To facilitate comprehension of the remainder of this report, the following subsections provide some definitions and categories that are used throughout this document. The remainder of the document is organizes as follows: Section 2 describes all the defects fixed in PoR 14, Section 3 lists describes or summarizes the new user features added, and Section 4 lists other miscellaneous activities. Sections 5 and 6 list less relevant or indirect user support activities related to research and then anything else.

\subsection{Definitions}

\subsubsection{VERA-CS}

For the purposes of this milestone report VERA-CS constitutes the following components:

- COBRA-TF

- MPACT

- ORIGEN

- VERAIn

- Cross section library data for MPACT 
Discussion of work related to other components such as: BISON, MAMBA, Tiamat, Cicada, and Shift, and VERAView are not included.

Additionally, user support activities related to providing installations or releases to users are not discussed in this report. There is a separate milestone (L3:PHI.INF.P14.04) and report [1] documenting these activities over PoR 14.

\subsubsection{User support activity}

This term is used in a very broad sense to encompass any activity that is performed to directly or indirectly provide support to a user.

\subsubsection{Defect}

A defect constitutes a problem with an existing feature that does not work as intended. These are typically identified by users.

\subsubsection{Feature}

A feature constitutes a capability that was not previously available that is requested by a user or on a users' behalf.

\subsection{Categories of User Support Activities}

\subsubsection{Direct support}

Activities that provide direct support include things like: providing an install for a user on some particular platform, fixing a defect, or adding a feature with a component in the input.

\subsubsection{Indirect support}

Activities that would be examples of indirect support are things like: updating the theory manual or documentation, developing a new algorithm that allows the code to run faster, improving nuclear data, evaluating or assessing the accuracy of an existing model, or adding a more rigorous numerical method. 


\section{DEFECTS}

This section summarizes all the defects discovered and fixed during the PoR. Each subsection lists the defects relevant to the components of VERA-CS.

A total of 56 new defects were reported, and a total of 34 defects were resolved.

\subsection{MPACT}

Table 1 lists all new defects reported for MPACT. There were 37 defects reported. Table 2 lists all defects closed for MPACT. There were 23 defects that were resolved.

Table 1. New defects for MPACT reported in PoR 14

\begin{tabular}{|c|c|}
\hline $\begin{array}{l}\text { PHI Kanban } \\
\text { Ticket \# }\end{array}$ & Ticket Description \\
\hline 4433 & (Defect) MPACT segfaults in some cases when using threads with rectangular pin meshes \\
\hline 4435 & (Defect) resonance option for non-resonance isotopes \\
\hline 4436 & (Defect) UIUC core follow transient case is crashing \\
\hline 4438 & (Defect) Problem 9 mini has been failing since 9/26/16 \\
\hline 4511 & (Defect) ThermalExpandXML does not expand user axial mesh \\
\hline 4518 & (Defect) NaN error with Power Normalization when using zero Xenon \\
\hline 4524 & (Defect) MPACT testPlanarSynthesis failing on UM Cl \\
\hline 4542 & (Defect) Thermal Expansion of Clad Inner Radius is wrong for IFBA \\
\hline 4557 & Fix valgrind defects in MPACT Nodal Sweeper \\
\hline 4561 & (Defect) IFBA rods are not thermally expanded correctly \\
\hline 4562 & (Defect) Thermal expansion code can create different pin pitches in different assembly types \\
\hline 4563 & (Defect) Axial thermal expansion is not production ready \\
\hline 4564 & (Defect) Refined ray spacing for IFBA is limited by memory requirements for 1000 core models \\
\hline 4565 & (Defect) Full symmetry is non-functional for some problems \\
\hline 4566 & (Defect) Isotope edits don't function for spatial decomposition \\
\hline 4567 & (Defect) Isotope edits don't function without depletion \\
\hline 4570 & (Defect) Axial remeshing works but the ends of the fuel stacks cannot be different \\
\hline 4572 & (Defect) MPACT speedups not reliable for reload cycles \\
\hline 4573 & (Defect) Isotope edits for inserts on the line of symmetry are half of the correct value \\
\hline 4583 & (Defect) Non-convergence for mid-Cycle depletion statepoint using Hybrid SP3 method \\
\hline 4584 & (Defect) Error with reduced diameter control rod tips \\
\hline 4585 & (Defect) MAMBA-1D fails when modelling a mid-cycle shutdown with zero power input \\
\hline 4622 & (Defect) Set default shielder ray spacing in future releases \\
\hline 4668 & (Defect) Use of 'mod' as a material name in standard input changes results \\
\hline 4671 & (Defect) Thermal expansion produces error with multiple IFBA materials \\
\hline 4696 & (Defect) op_date in [STATE] block should be unset with depletion \\
\hline 4697 & (Defect) reset_sol can not be used in two consecutive blocks \\
\hline 4698 & $\begin{array}{l}\text { (Defect) Assembly Pin Data Pin Power Edits segfault and do not identify correct symmetry for } \\
\text { standard input }\end{array}$ \\
\hline 4704 & $\begin{array}{l}\text { (Defect) Available Partition Table in MPACT output does not reflect the options for EXPLICITRADIAL } \\
\text { scheme }\end{array}$ \\
\hline 4771 & (Defect) Resonance data interpolation and B-10 depletion in the simplified AMPX capability \\
\hline 4776 & (Defect) Error reading multiple restart files and silent errors reading restart file \\
\hline
\end{tabular}




\begin{tabular}{|l|l|}
\hline 4791 & (Defect) Futility doesn't compile without MPACT \\
\hline 4797 & (Defect) Core map in HDF5 output is not correct for 16x16 assembly \\
\hline 4810 & (Defect) Issues with parallel VERA-CS transient calculations \\
\hline 4813 & (Defect) Isotope merging problem for O-16 in UO2 +Er2O3 for the SAMPX capability \\
\hline 4846 & (Defect) Fix assm_map usage for shuffles \\
\hline 4852 & (Defect) Wrong answer when setting boron to zero in stacked cases \\
\hline
\end{tabular}

Table 2. Closed defects for MPACT reported in PoR 14

\begin{tabular}{|c|l|c|}
\hline $\begin{array}{c}\text { PHI Kanban } \\
\text { Ticket \# }\end{array}$ & \multicolumn{1}{|c|}{ Ticket Description } & $\begin{array}{c}\text { Status/ } \\
\text { Resolution }\end{array}$ \\
\hline 4566 & (Defect) Isotope edits don't function for spatial decomposition & fixed \\
\hline 3582 & (Defect) Make sure all STATE input variables are updated in each calculation & fixed \\
\hline 4106 & (Defect) Pin Exposures Equal to Zero After Restart & fixed \\
\hline 4393 & (Defect) Bug in Control Rod Volume Correction & fixed \\
\hline 4433 & (Defect) MPACT segfaults in some cases when using threads with rectangular pin meshes & fixed \\
\hline 4435 & (Defect) resonance option for non-resonance isotopes & fixed \\
\hline 4436 & (Defect) UIUC core follow transient case is crashing & fixed \\
\hline 4438 & (Defect) Problem 9 mini has been failing since 9/26/16 & fixed \\
\hline 4524 & (Defect) MPACT testPlanarSynthesis failing on UM Cl & fixed \\
\hline 4565 & (Defect) Full symmetry is non-functional for some problems & fixed \\
\hline 4622 & (Defect) Set default shielder ray spacing in future releases & fixed \\
\hline 4810 & (Defect) Issues with parallel VERA-CS transient calculations & fixed \\
\hline 4813 & (Defect) Isotope merging problem for O-16 in UO2 +Er2O3 for the SAMPX capability & fixed \\
\hline 4852 & (Defect) Wrong answer when setting boron to zero in stacked cases & fixed \\
\hline 3460 & (Defect) Fix P2 scattering error with external coupling & wontfix \\
\hline 4585 & (Defect) MAMBA-1D fails when modelling a mid-cycle shutdown with zero power input & wontfix \\
\hline 3840 & (Defect) bug in control rod treatment when poison boundary aligns with fuel & in review \\
\hline 4511 & (Defect) ThermalExpandXML does not expand user axial mesh & in review \\
\hline 4542 & (Defect) Thermal Expansion of Clad Inner Radius is wrong for IFBA & in review \\
\hline 4562 & (Defect) Thermal expansion code can create different pin pitches in different assembly types & in review \\
\hline 4671 & (Defect) Thermal expansion produces error with multiple IFBA materials & in review \\
\hline 4771 & (Defect) Resonance data interpolation and B-10 depletion in the simplified AMPX capability & in review \\
\hline 4776 & (Defect) Error reading multiple restart files and silent errors reading restart file & in review \\
\hline
\end{tabular}

\subsection{COBRA-TF}

Table 3 lists all new defects reported COBRA-TF. There were 17 new defects reported. Table 4 lists all defects closed for COBRA-TF. There were a total of 9 defects resolved.

Table 3. New defects for COBRA-TF reported in PoR 14

\begin{tabular}{|c|l|}
\hline $\begin{array}{c}\text { PHI Kanban } \\
\text { Ticket \# }\end{array}$ & \multicolumn{1}{c|}{ Ticket Description } \\
\hline 4439 & (Defect) Test_RodMesh failing in STATIC build \\
\hline 4442 & (Defect) Input for rod radiative heat transfer model does not work \\
\hline 4457 & (Defect) CTF manuals not getting updated on website \\
\hline 4503 & (Defect) Heat balance output file showing wrong power to model \\
\hline 4509 & (Defect) Fix mistake in BFBT C2A model \\
\hline 4532 & (Defect) CTF HDF5 reader no longer works with new version of VERA-CS \\
\hline
\end{tabular}




\begin{tabular}{|l|l|}
\hline 4538 & (Defect) Fix VUQCore_CTF_verain_small_singlerod_HFP \\
\hline 4549 & (Defect) CTF standalone build tests failing (but not VERA-CS builds) \\
\hline 4552 & (Defect) Sort through standalone CTF test failures on Redhat \\
\hline 4554 & (Defect) Biasi correlation not consistent with literature \\
\hline 4571 & (Defect) Release Candidate 0 is using COBRATF.ini rather than the new CTF preprocessor defaults \\
\hline 4673 & (Defect) Issues with multistate diff tool printout \\
\hline 4694 & (Defect) xml2ctf doesn't get centroids right for boundary channels with shroud \\
\hline 4754 & (Defect) bwr-p6-test doesn't build with xml2ctf anymore \\
\hline 4838 & (Defect) linear heat rate does not update every state in CTF HDF5 output \\
\hline 4860 & (Defect) VERA-CS crashes when 'parallel' not in COBRA-TF block \\
\hline 4863 & (Defect) Fix BFBT P6 series input decks \\
\hline
\end{tabular}

Table 4. Closed defects for COBRA-TF reported in PoR 14

\begin{tabular}{|c|l|c|}
\hline $\begin{array}{c}\text { PHI Kanban } \\
\text { Ticket \# }\end{array}$ & \multicolumn{1}{c|}{ Ticket Description } & $\begin{array}{c}\text { Status/ } \\
\text { Resolution }\end{array}$ \\
\hline 4076 & (Defect) Pin steam rate not printed correctly to HDF5 file for symmetry cases & fixed \\
\hline 4125 & (Defect) Annular/mist interfacial drag model in CTF is not consistent with theory manual & fixed \\
\hline 4284 & (Defect) Interfacial drag/heat transfer not implemented correctly & fixed \\
\hline 4367 & (Defect) Specifying zero noncondensable gas void in CTF crashes code & fixed \\
\hline 4407 & (Defect) New CTF Preprocessor does not support older cases & fixed \\
\hline 4439 & (Defect) Test_RodMesh failing in STATIC build & fixed \\
\hline 4538 & (Defect) Fix VUQCore_CTF_verain_Small_singlerod_HFP & fixed \\
\hline 4571 & $\begin{array}{l}\text { (Defect) Release Candidate 0 is using COBRATF.ini rather than the new CTF preprocessor } \\
\text { defaults }\end{array}$ & wontfix \\
\hline 4403 & (Defect) BWR preproc uses geometric center instead of centroids & in review \\
\hline
\end{tabular}

\subsection{ORIGEN}

Table 5 lists all new defects reported for ORIGEN. Table 6 lists all defects closed for ORIGEN. There was a total of 1 new defect reported and one defect resolved.

Table 5. New defects for ORIGEN reported in PoR 14

\begin{tabular}{|c|c|}
\hline $\begin{array}{c}\text { PHI Kanban } \\
\text { Ticket \# }\end{array}$ & Ticket Description \\
\hline 4569 & (Defect) Lithium depletion is degraded with $4.2 \mathrm{~m} 5$ cross section library \\
\hline
\end{tabular}

Table 6. Closed defects for ORIGEN reported in PoR 14

\begin{tabular}{|c|l|c|}
\hline $\begin{array}{c}\text { PHI Kanban } \\
\text { Ticket \# }\end{array}$ & Ticket Description & $\begin{array}{c}\text { Status/ } \\
\text { Resolution }\end{array}$ \\
\hline 4566 & (Defect) Isotope edits don't function for spatial decomposition & in review \\
\hline 4569 & (Defect) Lithium depletion is degraded with 4.2m5 cross section library & in review \\
\hline
\end{tabular}




\subsection{VERAIn}

Table 7 lists all new defects reported VERAIn. Table 8 lists all defects closed for VERAIn. There was a total of 1 new defect reported and one defect closed.

Table 7. New defects for VERAIn reported in PoR 14

\begin{tabular}{|c|c|}
\hline $\begin{array}{c}\text { PHI Kanban } \\
\text { Ticket \# }\end{array}$ & Ticket Description \\
\hline 4672 & (Defect) Cannot change the incore detector type through input \\
\hline
\end{tabular}

Table 8. Closed defects for VERAIn reported in PoR 14

\begin{tabular}{|c|c|c|}
\hline $\begin{array}{c}\text { PHI Kanban } \\
\text { Ticket \# }\end{array}$ & Ticket Description & $\begin{array}{c}\text { Status/ } \\
\text { Resolution }\end{array}$ \\
\hline 4672 & (Defect) Cannot change the incore detector type through input & wont fix \\
\hline
\end{tabular}




\section{ACTIVITIES RELATED TO OTHER MILESTONES}

This section summarizes the tickets documenting work related to other milestones. The milestones that received user support during this PoR are given in Table 9.

Table 9. Milestones supported during PoR 14

\begin{tabular}{|c|l|}
\hline CASL Milestone & \multicolumn{1}{|c|}{ Description } \\
\hline L2:RTM.P14.01 & $\begin{array}{l}\text { Develop and deliver nuclear cross section data libraries supporting Pressurized Water Reactor (PWR) } \\
\text { and Boiling Water Reactor (BWR) designs }\end{array}$ \\
\hline L2:RTM.P15.02 & Development of transient MPACT-CTF capability for RIA (with DNB) \\
\hline L3:PHI.VCS.P13.03 & Restart file improvements for performance and coupling \\
\hline L4:PHI.VCS.P14.01 & coupled MPACT+CTF for transient analysi \\
\hline L3:PHI.RIA.P15.01 & Initial implementation of transient VERA-CS \\
\hline L3:AMA.RX.P14.08 & Evaluation and Testing of VERA for CE System-80 Design \\
\hline ACT:PHI.FY17.02 & Training \\
\hline
\end{tabular}

\subsection{L2:RTM.P14.01}

This milestone was about delivering an improved cross section capability for VERA-CS/MPACT. This involved the generation of new cross section libraries, the addition of a capability to read a simplified AMPX library, and substantial evaluation of these new libraries. Improving and delivering the new data is direct user support. The additional features and evaluation is indirect user support. For a complete description of this milestone work please see the milestone report [2]. A list of relevant tickets is provided in the table below.

Table 10. Tickets supporting L2:RTM.P14.01 completed during PoR 14

\begin{tabular}{|c|l|l|l|}
\hline $\begin{array}{c}\text { PHI Kanban } \\
\text { Ticket\# }\end{array}$ & \multicolumn{1}{|c|}{ Description } & \multicolumn{1}{|c|}{$\begin{array}{c}\text { Status/ } \\
\text { Resolution }\end{array}$} & Support \\
\hline 4221 & Generate 51-and 252-group libraries for MPACT in July 2016 & fixed & direct \\
\hline 4245 & Automate the reactivity analysis for MPACT cross section library & fixed & direct \\
\hline 4380 & Improve the ENDF/B-7.0 and 7.1 MPACT 51-g libraries & fixed & direct \\
\hline 4469 & Merge Simplified AMPX to master and assess accuracy & fixed & direct \\
\hline 4495 & Extends the simplified AMPX capability for depletion & fixed & direct \\
\hline 4678 & Print group-wise reaction rate error in text with the reaction rate analysis tool & fixed & direct \\
\hline 4526 & Split natural isotopes for the simplified AMPX capability & in review & direct \\
\hline 4240 & Generate MPACT-MCNP pincell comparisons for depleted cases & fixed & indirect \\
\hline 4276 & Investigate large eigenvalue sensitivities to number of radial rings in fuel & fixed & indirect \\
\hline 4363 & Update MCNP-MPACT pincell comparison report for 51g library & fixed & indirect \\
\hline 4364 & Update MCNP-MPACT assembly comparison report for 51g library & fixed & indirect \\
\hline 4452 & Evaluate mpact51g_v4.2m2 library & fixed & indirect \\
\hline 4461 & Evaluate memory and computing time requirements for new AMPX library & fixed & indirect \\
\hline 4492 & Evaluate mpact51g_v4.2m4 library & fixed & indirect \\
\hline 4743 & BWR benchmark calculations by using the SAMPX 51 \& 252-g libraries & fixed & indirect \\
\hline 4392 & Generate isotopic analysis comparisons with data and SCALE codes & in review & indirect \\
\hline 4577 & Run DIMPLE Criticals with mpact51g_70_v4.2m3_10272016_sph.fmt & in review & indirect \\
\hline
\end{tabular}




\subsection{L2:RTM.P15.02}

This milestone is about providing an upgraded transient capability. Some initial effort was provided to support this milestone. The full extent of the efforts related to this milestone will be documented in the future milestone report. The list of relevant tickets are given in the table below.

Table 11. Tickets supporting L2:RTM.P15.02 completed during PoR 14

\begin{tabular}{|c|l|l|l|}
\hline $\begin{array}{c}\text { PHI Kanban } \\
\text { Ticket \# }\end{array}$ & \multicolumn{1}{|c|}{ Description } & $\begin{array}{c}\text { Status/ } \\
\text { Resolution }\end{array}$ & \multicolumn{1}{|c|}{ Support } \\
\hline 4812 & Implement MPACT edits for transient calculations & in progress & direct \\
\hline 4493 & Improve and Document Transient Input Cards & closed & direct \\
\hline & Enable exponential transformation & closed & direct \\
\hline
\end{tabular}

\subsection{L3:PHI.VCS.P13.03}

This milestone was about delivering improved features to the restart capability. The full description of this work can be found in the milestone report [3]. This work constitutes direct user support. The relevant tickets completed during PoR 14 are given in the table below.

Table 12. Tickets supporting L3:PHI.VCS.P13.03 completed during PoR 14

\begin{tabular}{|c|l|l|l|}
\hline $\begin{array}{c}\text { PHI Kanban } \\
\text { Ticket \# }\end{array}$ & \multicolumn{1}{|c|}{ Description } & $\begin{array}{c}\text { Status/ } \\
\text { Resolution }\end{array}$ & Support \\
\hline 3575 & Add axial re-mesh option during core shuffle & fixed & direct \\
\hline 3736 & Add MAMBA scratch arrays to restart file & in review & direct \\
\hline 4211 & Write all STATE values to the HDF output file and restart file & fixed & direct \\
\hline 4314 & Read all STATE values from the restart file to the state type & fixed & direct \\
\hline
\end{tabular}

\subsection{L4:PHI.VCS.P14.01}

This work was primarily research, but some of the efforts here were leveraged for the L3:PHI.RIA.P15.01 milestone. See the section on the L3:PHI.RIA.P15.01 milestone for more detail.

\subsection{L3:PHI.RIA.P15.01}

This milestone was about providing an initial capability to run VERA-CS (e.g. MPACT and CTF coupled) for transients. For a complete description of this work see the milestone report [4]. The list of tickets relevant to this milestone are given in the table below.

Table 13. Tickets supporting L3:PHI.RIA.P15.01 completed during PoR 14

\begin{tabular}{|c|l|l|l|}
\hline $\begin{array}{c}\text { PHI Kanban } \\
\text { Ticket \# }\end{array}$ & \multicolumn{1}{|c|}{ Description } & $\begin{array}{c}\text { Status/ } \\
\text { Resolution }\end{array}$ & Support \\
\hline 4256 & Merge MPACT Transient branch into master & closed & direct \\
\hline 4628 & Implement basic coupled transient capability in CTF & closed & direct \\
\hline 4640 & Modify MPACT to handle transient coupled with CTF & closed & direct \\
\hline
\end{tabular}

\subsection{L3:AMA.RX.P14.08}

This milestone was about extending the capability of VERA-CS to combustion engineering designs. During this work, several issues were identified and addressed. This constitutes direct user support. Further information about this milestone can be found in the milestone report [5]. The list of tickets supporting this milestone are given in the table below. 
Table 14. Tickets supporting L3:AMA.RX.P14.08 completed during PoR 14

\begin{tabular}{|c|l|l|l|}
\hline $\begin{array}{c}\text { PHI Kanban } \\
\text { Ticket \# }\end{array}$ & \multicolumn{1}{|c|}{ Description } & $\begin{array}{c}\text { Status/ } \\
\text { Resolution }\end{array}$ & \multicolumn{1}{c|}{ Support } \\
\hline 4735 & Add coupling support between MPACT/CTF for CE-16 models & in review & direct \\
\hline 4477 & Allow "large4" control rods for CE-16x16 lattices & fixed & direct \\
\hline 4517 & Generate the v4.2m5 MPCT 51-g libraries including Er-162, 164 and 170 & fixed & direct \\
\hline
\end{tabular}

\subsection{ACT:PHI.FY17.02}

This is a PHI milestone about administering training. The relevant training activities from PoR 14 included a training provided by Scott Palmtag to engineers from WEC. 


\section{MISCELLANEOUS USER SUPPORT ACTIVITIES}

The following table lists all other tickets that do not fit in any of the above categories.

Table 15. Miscellaneous support activities completed during PoR 14

\begin{tabular}{|c|c|c|c|}
\hline $\begin{array}{l}\text { PHI Kanban } \\
\text { Ticket \# }\end{array}$ & Description & $\begin{array}{c}\text { Status/ } \\
\text { Resolution }\end{array}$ & Support \\
\hline 3445 & Add ability to input material mixtures by atom density & fixed & direct \\
\hline 3473 & Run case with thermal expansion and quantify effects on ITC & fixed & indirect \\
\hline 3594 & Add Warning messages to MPACT & in review & direct \\
\hline 3599 & Add CTF preprocessor support for unique instrument tubes & fixed & direct \\
\hline 3603 & Integrate Burnup-dependent Fuel Conductivity in CTF & fixed & direct \\
\hline 3674 & Add ability to model in-core detectors for Watts Bar Unit 2 & fixed & direct \\
\hline 4090 & Add capability to compute water + soluble boron by two methods & fixed & direct \\
\hline 4158 & Improve Full Core Partition Performance in MPACT & wontfix & indirect \\
\hline 4159 & Design Control Rod Depletion in MPACT & fixed & indirect \\
\hline 4169 & Design and Prototype Fortran Interfaces for Main Trilinos Solvers & fixed & indirect \\
\hline 4188 & Make quarter rotational symmetry model for parallel $4 \mathrm{x}$ option in CTF & fixed & direct \\
\hline 4193 & Add support for vanadium_response and vanadium_mesh & in review & direct \\
\hline 4206 & Move MPACT-specific input files from VERAIn repo to MPACT repo & fixed & indirect \\
\hline 4209 & Implement Embedded Pin Cell Solver(s) for Partially Inserted Rods & fixed & indirect \\
\hline 4236 & Add grid effects on TKE for CTF/MAMBA simulations & fixed & direct \\
\hline 4257 & Add comparison to BFBT axial void measurements & invalid & indirect \\
\hline 4261 & Consolidate Logic for Executing Subgroup & fixed & indirect \\
\hline 4286 & Evaluate what needs to be done to turn on dynamic gap conductance from VERAln & fixed & indirect \\
\hline 4305 & Write MPACT Fast Flux to HDF5 File & fixed & direct \\
\hline 4320 & Fix axial mesh tolerance in MPACT \& CTF & in review & direct \\
\hline 4321 & BWR Control Blade Movement Implementation & fixed & direct \\
\hline 4345 & Perform verificaiton of fuel temperature solution & fixed & indirect \\
\hline 4353 & Implement shuffle map label format input option & fixed & dri \\
\hline 4357 & Update Theory Manual To Include Chapter for 1D-Axial Nodal Kernels & fixed & indirect \\
\hline 4368 & Make CTF assume uniform axial power if no power profile given & fixed & indirect \\
\hline 4378 & Inplement VERA input for MOX & fixed & direct \\
\hline 4391 & Add verification testing to new residual formulation & fixed & indirect \\
\hline 4423 & Demonstrate VERA-CS/BISON Load-Follow on Single rod & fixed & indirect \\
\hline 4460 & Change default for react2xml to use --Init & fixed & direct \\
\hline 4475 & Add capability to produce normalized MPACT FSR mesh output & in review & direct \\
\hline 4476 & Add Erbia mixing option to MPACT & fixed & direct \\
\hline 4501 & Implement PETSc Nonlinear Solver(SNES) and Eigenvalue Solver & fixed & indirect \\
\hline 4527 & Allow Partition Data to be Processed From Input, Without External File & fixed & direct \\
\hline 4531 & Update Theory Manual to Include 1-group Subgroup & fixed & indirect \\
\hline 4533 & $\begin{array}{l}\text { Update Theory Manual on Overall Iteration Scheme (Power Iterations, Wielandt shift, } \\
\text { and Convergence Criteria) }\end{array}$ & fixed & indirect \\
\hline 4541 & COBRA_TF Multistate issues & fixed & direct \\
\hline 4551 & Add support to ctfReader for chan.out files with no table 3 & fixed & direct \\
\hline 4586 & Add Transient chapter to MPACT Theory Manual & fixed & indirect \\
\hline 4618 & Add cmfd flux update relaxation to MPACT \& VERA input & fixed & direct \\
\hline 4753 & Expand pyCTF reader to read bundle-average properties & in review & direct \\
\hline 4762 & Fix C5G7 and Takeda Inputs in Repo & fixed & indirect \\
\hline 4794 & Enhance the HELIOS library processing for the upcoming HELIOS-2 library & in review & direct \\
\hline
\end{tabular}




\begin{tabular}{|l|l|l|l|}
\hline 4855 & Add defaults for xlabel/ylabel & fixed & direct \\
\hline 4871 & Write utility to detect feedback for use in scripts & in review & direct \\
\hline
\end{tabular}

\section{CONCLUSIONS}

During PoR 14 there were approximately 108 PHI Kanban tickets related to user support activities, either directly or indirectly. In total there were 108 tickets related to user support activities for VERA-CS. There were 56 new reported defects and 34 defects fixed in PoR 14. 44 tickets were related to miscellaneous user requests and did not directly support any milestones. Work was also performed for 30 tickets related to 7 milestones. A training was also given to WEC. 


\section{REFERENCES}

[1] “L3 PHI.INF.P14.04 Completion Memo,” CASL Memo, CASL-U-2017-1304-000, March (2017).

[2] K. S. Kim, et al., "Development of the V4.2m5 and V5.0m0 Multigroup Cross Section Libraries for MPACT for PWR and BWR," CASL Technical Report, CASL-U-2017-1280000, Feb. (2017).

[3] B. Kochunas, D. Jabaay, and R. Salko, "Restart File Improvements for MPACT," CASL Technical Report, CASL-U-2016-1120-000, Jan. (2017).

[4] A. Wysocki, et al., "Initial Implementation of Transient for VERA-CS," CASL Technical Report, CASL-U-2017-1303-000, March (2017).

[5] Scott Palmtag, "Evaluation and Testing of VERA for CE System-80 Design," CASL Technical Report, CASL-U-2017-1300-000, March (2017). 